\title{
COLLABORATIVE METACOGNITIVE ACTIVITIES, STUDENTS' SOCIALLY MOTIVATED METACOGNITIVE EXPERIENCES, AND STOICHIOMETRIC PROBLEM-SOLVING
}

\author{
Fitzgerald L. Fabelico
}

Professor, College of Education, Nueva Vizcaya State University, Bambang, Nueva Vizcaya, Philippines.

Email: fitzgeraldfabelico@yahoo.com

Article History: Received on $21^{\text {st }}$ April 2020, Revised on $24^{\text {th }}$ June 2020, Published on $17^{\text {th }}$ July 2020

\begin{abstract}
Purpose of the study: This study investigates the effect of collaborative metacognitive activities (CMA) on students' socially motivated metacognitive experiences (SMME) during stoichiometric problem-solving.

Methodology: This descriptive research employed mixed methods. To document and analyze students' CMA, dual coding process, discourse analysis, and social network analyses were used. There were 18 participants selected purposively and grouped homogeneously based on their academic ability.

Main Findings: The findings revealed that CMA affects students' SMME quantitatively in stoichiometric problemsolving across ability groups and chemistry tasks. Successful collaboration occurs when feedback requests and other monitoring responses on the assessment of understanding and strategy influences students' estimates of solution correctness and feeling of satisfaction across ability groups and affects the feeling of difficulty across chemistry tasks.
\end{abstract}

Applications of this study: This study will help teachers design student activities that could capitalize on the advantages of collaborative metacognitive activities to help students achieve successful collaboration during problem-solving activities not only in chemistry but also in the allied fields.

Novelty/Originality of this study: This study explains clearly the relevance of CMA and SMME during stoichiometric problem-solving. Moreover, this study elucidated the mechanism of successful and unsuccessful collaboration used by the different groups of students in solving the algorithmic and conceptual chemistry tasks.

Keywords: Chemistry, Collaboration, Metacognition, Metacognitive Experiences, Problem-solving, Stoichiometry.

\section{INTRODUCTION}

Stoichiometry is important in understanding the essential concepts of chemistry (Etokeren et al., 2019; Gupta, 2019; Iriani et al., 2019; Sangguro et al., 2020; Sujak \& Sarojini, 2017). Numerous researches underscored that stoichiometry is one of the most challenging topics for students across educational levels (Aydin-Gunbatar \& Kalender, 2019; Gulacar et al., 2019; Lausin, 2020; Scott, 2020; Shadreck \& Enunuwe, 2018). Stoichiometric problem-solving requires a sound conceptual understanding of the quantitative relationships, mole ratio, balanced chemical equations, limiting and excess reagents, and theoretical yield (Dahsah \& Coll, 2013; Makhechane \& Qhobela, 2019). Apart from conceptual understanding, this is also related to students' metacognition (Fabelico, 2014; Ijirana \& Supriadi, 2018; Syahmani, 2015).

Metacognition involves how learners think about their thought process (Flavel, 1979), identify the learning strategies that work best for them, and consciously on how to manage their learning within a given period. Likewise, metacognition involves the regulation and mentalizing of one's own and others' cognitive processes (Frith, 2012). Metacognition also includes the monitoring and control functions. The monitoring function includes metacognitive knowledge and metacognitive experiences (Flavel, 1979). The control function consists of the metacognitive skills or strategies (Efklides, 2006, 2009; 2014; Efklides et al., 1999). Metacognitive knowledge is the declarative knowledge of the task and procedures about the cognitive functions (Flavel, 1979). Conversely, metacognitive skills pertain to procedural knowledge (Efklides, 2009) or executive processes (Efklides, 2002). Metacognitive skills are useful not only in enhancing a deeper understanding of abstract concepts but also in the regulation of cognitive processes during problem-solving (Ijirana \& Supriadi, 2018; Syahmani, 2015).

Several studies stressed that the social interactions could develop the facets of metacognition through problem-solving processes (Salonen et al., 2005; Siburt et al., 2011). Social interaction facilitates the shared understanding and construction of knowledge through social negotiations of views and meanings (Ramadhan \& Pratana, 2020). The educational dimension (type of tasks) and social dimensions (grouping of students) of social interaction play important in problem-solving processes (Kreijns et al., 2002).

When social interaction activates metacognitive processes during problem-solving, this results in collaborative metacognitive activity (Goos et al., 2002). Collaborative metacognitive activity (CMA) could either be successful or unsuccessful. Successful collaboration is characterized by the utterances, which are simultaneously metacognitive functions and transactive structures (Goos et al., 2002). Other studies that deals with the socio-cognitive aspect of metacognition refers to social regulation (Salonen et al., 2005), socially mediated-metacognition (Goos et al., 2002), 
socially shared-metacognition (Iiskala et al., 2015), group metacognition (Siegel, 2011), and social metacognition (Chen et al., 2012).

During social interactions, metacognitive experience has a significant effect on the coregulation of learning (Salonen et al., 2005). Metacognitive experiences are commonly known as online metacognition and affective experiences (Efklides, 2006, 2009). Metacognitive experiences activate both metacognitive knowledge and metacognitive strategies before, during, or after cognitive processing (Akama \& Yamauchi, 2004; Asik \& Erktin, 2019; Choy et al., 2019; Choy et al., 2020; Flavel, 1979; Mwambe \& Kamioka, 2019; Norman \& Furnes, 2016; Radmehr \& Drake, 2018; Roeberts et al., 2019; Thomas \& McRobbie, 2012). Moreover, metacognitive experiences comprise online-specific knowledge, metacognitive feelings, and metacognitive judgments as cognition progresses (Efklides, 2006; Sanna \& Schwarz, 2006). Metacognitive feelings include feelings of confidence, difficulty, familiarity, liking, and satisfaction. Metacognitive judgments include estimates of effort, error, and solution correctness (Efklides, 2002, 2006, 2009, 2014). Online taskspecific knowledge refers to the awareness of task features and task-related procedures and strategies during cognitive processing (Efklides, 2006).

Metacognitive experiences were found to trigger socially-shared metacognition (Efklides, 2014). However, there were limited studies on social metacognition (Dindar et al., 2020a; Efklides, 2014; Iiskala et al., 2015). There is no existing literature that deals on the effect of social metacognition on group metacognitive experiences during chemistry problemsolving processes. Thus, this study aimed to investigate how collaborative metacognitive activities affect students' socially motivated metacognitive experiences during stoichiometric problem-solving processes. Furthermore, this study also elucidated the mechanism of successful and unsuccessful collaboration during stoichiometric problem-solving across ability groups and chemistry tasks. Socially motivated metacognitive experiences refer to the metacognitive experiences of the participants during collaborative metacognitive activities.

\section{METHODOLOGY}

This descriptive research is similar to the previous study conducted by Fabelico (2014) with some modifications. The participants were the college freshmen students of a premier university in Nueva Vizcaya, Philippines. The 18 participants were selected purposely. These participants were grouped homogeneously as low, average, or high ability groups based on the results of the college admission examination. The participants were grouped into six groups composed of the triad or three gender-balanced members per group. Triads are more stable because the members exhibit cooperative learning processes during social interactions (Stamovlasis et al., 2006).

Similar to Fabelico (2014), the instruments used in this study include the retrospective Metacognitive Experience Questionnaires (MEQ), group chemistry tasks (GCT), group thinking journal (GTJ), and the researcher's observation journal (ROJ). The MEQ has a reliability coefficient of $\alpha=.82$ (Efklides et al., 1999). The GCT includes the algorithmic and conceptual stoichiometry tasks (Chiu, 2001; Wood \& Breyfogle, 2006). The GCT were validated by experts and are reliable $(W=.64, p<.05)$. Both the GTJ and ROJ were used to identify the group that exhibited successful and unsuccessful collaboration during their GCT.

The members of the successful and unsuccessful groups answer the MEQ individually after the GCT and GTJ. The data from the MEQ are used as the students' socially motivated metacognitive experiences (SMME).

The quantitative and qualitative methods of data analyses were employed to facilitate the transcription of students' utterances. These methods include the process of dual coding, discourse analyses, and interaction matrix analyses (Fabelico, 2014; Goos et al., 2002; Stamovlasis et al., 2006). Student utterances are classified as metacognitive function, transactive structure, and collaborative metacognitive activities (Goos et al., 2002). Metacognitive functions (MF) are metacognitive acts. Metacognitive functions involve the generation of a new idea, assessment of strategy, assessment of results, and assessment of understanding (Fabelico, 2014; Goos et al., 2002). Transactive structures (TS) are transactive acts, communicative discourses, or utterances. that include feedback requests, self-disclosure, and other-monitoring responses (Fabelico, 2014; Goos et al., 2002). When metacognitive functions and transactive functions converge simultaneously, this is considered as a collaborative metacognitive activity (CMA). This CMA can either leads to successful or unsuccessful collaboration during problem-solving processes (Goos et al., 2002). The participants verified the student transcripts, both verbal and non-verbal cues. The researcher categorized the transcripts into MF, TS, and CMA. The participants and the experts validated the categorized transcripts. The inter-judge reliability coefficient of the MF $(k=.95, p<.05)$ and TS $(k=.97, p<.05)$ yielded very high results for the dual coding and categorization of student transcripts.

The researcher used micro-scale analyses of the CMA and interaction matrices to have an in-depth analyses of the social metacognition among the participants across ability groups (Goos et al., 2002; Stamovlasis et al., 2006). The researcher also identified the triads that exemplified successful and unsuccessful collaboration during stoichiometric problemsolving based on the data of micro-scale analyses and interaction matrices.

Since the members in the triads form a network of interactions, then the social network analysis was employed. The social network analysis (SNA) is a tool used to explain the various aspects of individual participation (Quatman \& Chelladurai, 2008), the pattern of metacognitive interactions (Jagals \& Van der Walt, 2016; Hurme et al., 2006), and 
collaborative processes (Lawanto \& Santoso, 2013) among the participants in the group. The relational approach of SNA explains in an interpretative manner the metacognitive constructs and dynamic interactions among the participants (Quatman \& Chelladurai, 2008). This study used the relational approach of SNA.

With SNA, the structural balance theory explains the triadic relationships among the participants (Lou et al., 2013; Qian \& Adali, 2014). The types of relationships could either be balanced or unbalanced, positive, negative, or neutral relationships. The different network configurations and mechanisms include activity, closure, homophily, popularity, and reciprocity (Lou et al., 2013; Qian \& Adali, 2014). The Agent-Based Model was also used to describe the specific discourse pattern exhibited by the different triads as either dyadic, triadic, or leadership patterns (Koponen \& Nousiainen, 2018).

\section{RESULTS AND DISCUSSION}

Representative ability groups were selected purposely for in-depth analyses to have a profound understanding of the CMA among the participants. This section presents and discusses the results for the effect of CMA on SMME across ability groups and chemistry tasks.

\section{Collaborative Metacognitive Activities and Socially Motivated Metacognitive Experiences across Ability Groups}

As displayed in Figure 1, the high and average ability groups were considered as successful groups while the low ability group is an unsuccessful group. The CMA of the high ability group leads to successful collaboration that portrayed an "egalitarian dyadic leader pattern" (Koponen \& Nousiainen, 2018). The two dyads shared a joint partner who is considered the leader. Student H1 acted as the leader and controls the verbal interactions with $46 \%$ total number of utterances as compared to students $\mathrm{H} 2$ and $\mathrm{H} 3$ with $18 \%$ and $24 \%$ utterances, respectively. Although the mechanism is unbalanced, the collaboration is considered auspicious. The two dyads $\mathrm{H} 1 \leftrightarrow \mathrm{H} 2$ and $\mathrm{H} 1 \leftrightarrow \mathrm{H} 3$ showed homophilic strong positive ties and dyadic dependence with each other (Lou et al., 2013; Qian \& Adali, 2014). There was observable reciprocal dependence in the CMA among the students during problem-solving processes. Student H1 leads the group to have a CMA on giving feedback requests in the assessment of their understanding $(9.1 \%)$, strategies $(27.3 \%$, and results (36.4\%). Similarly, student $\mathrm{H} 1$ also assisted his co-learners to do other monitoring acts towards the assessment of results (27.3\%) during their chemistry tasks.

Synonymous to the high ability group, the average ability group exhibited successful collaboration but with an "egalitarian triadic pattern" (Koponen \& Nousiainen, 2018). In this balanced mechanism, all of the three links showed reciprocity with transitive triad or three-cycle closure. The three dyads $\mathrm{M} 1 \leftrightarrow \mathrm{M} 2, \mathrm{M} 1 \leftrightarrow \mathrm{M} 3$, and $\mathrm{M} 2 \leftrightarrow \mathrm{M} 3$, demonstrated homophilic strong positive ties and dyadic dependence with each pair (Lou et al., 2013; Qian \& Adali, 2014). These interactions resulted in mutual and reciprocal coregulation of CMA during problem-solving tasks. Student M2 had 43\% number of utterances as compared to M1 (33\%) and M3 (24\%). The average ability group showed a reciprocal, continuous cycle of social interactions among the members. The students gave feedback requests $(51 \%)$ and other monitoring responses (49\%) to assess their co-learner's strategy, results, and understanding of the chemistry tasks. The CMA that transpired among the participants included feedback requests on the assessment of understanding (19.7\%) and results (31.3\%). The CMA also includes other monitoring of assessment of understanding (29.5\%), strategy (13.8\%), and results $(6.0 \%)$.

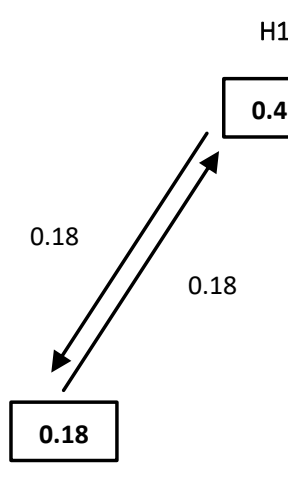

$\mathrm{H} 2$

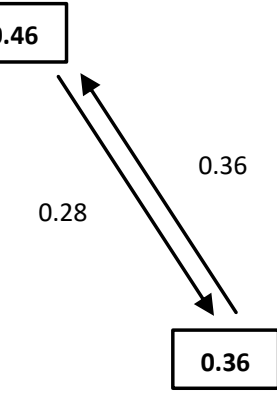

H3

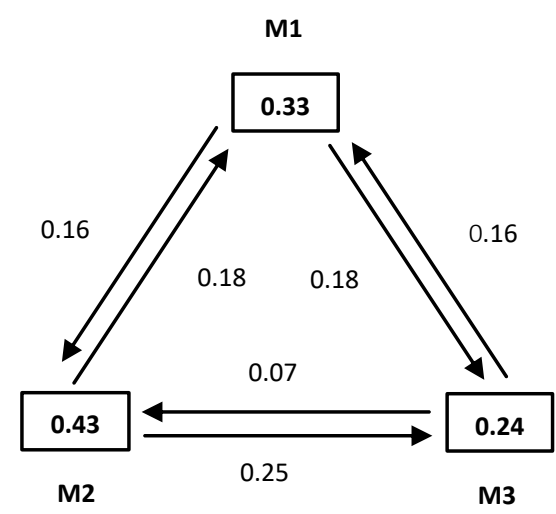

Average ability group (Successful collaboration)

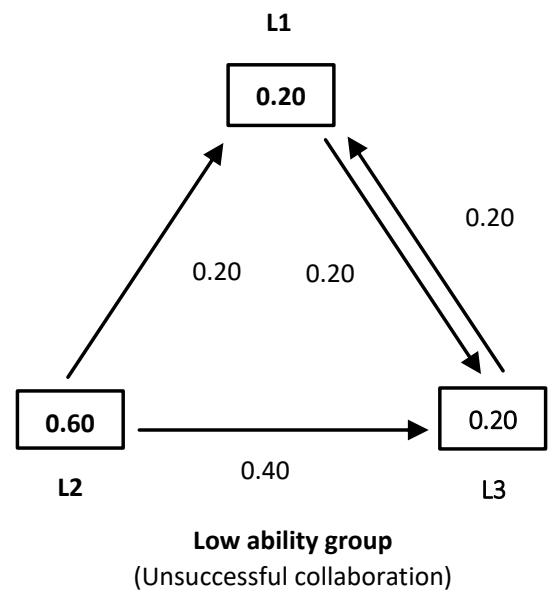

(Unsuccessful collaboration)

Figure 1: Collaborative metacognitive activities matrix of the participants across ability groups

Conversely, the results in Figure 1 revealed that the low ability group exhibited a modified "broker triad pattern" (Koponen \& Nousiainen, 2018) that resulted in unsuccessful collaboration. In this balanced mechanism, the two members L1 $\leftrightarrow \mathrm{L} 3$ are connected to the third member L2 by an outgoing link. In this case, the outgoing connection or out-2-star link was initiated by the third member L2. While students L1 and L3 had a dyadic dependence and homophilic strong positive relationship, student L2 failed to establish a reciprocal relationship with the other two members (Lou et 
al., 2013; Qian \& Adali, 2014). The result was an unsuccessful collaboration. Their CMA could explain the unsuccessful collaboration among the low ability group. These CMA are as follows: feedback requests on the assessment of understanding (20\%), strategy (20\%), and results (20\%), and other monitoring of assessment of results (40\%).

Table 1: Means and standard deviations of socially motivated metacognitive experiences across ability groups

\begin{tabular}{|c|c|c|c|c|c|}
\hline \multirow[t]{2}{*}{ Metacognitive Experiences } & & \multicolumn{3}{|c|}{ Ability Groups } & \multirow[t]{2}{*}{ Overall } \\
\hline & & High & Average & Low & \\
\hline \multirow[t]{2}{*}{ Feeling of Liking (FOL) } & $\overline{\mathrm{X}}$ & 3.67 & 4.00 & 3.67 & 3.78 \\
\hline & $\mathrm{SD}$ & .577 & .000 & .577 & .441 \\
\hline \multirow[t]{2}{*}{ Feeling of Difficulty (FOD) } & $\overline{\mathrm{x}}$ & 2.33 & 3.33 & 2.33 & 2.67 \\
\hline & SD & .577 & 1.15 & 1.52 & 1.12 \\
\hline \multirow[t]{2}{*}{ Estimate of Effort (EOE) } & $\overline{\mathrm{x}}$ & 2.33 & 3.67 & 3.67 & 3.22 \\
\hline & $\mathrm{SD}$ & .577 & .577 & .577 & .833 \\
\hline \multirow[t]{2}{*}{ Estimate of Time (EOT) } & $\overline{\mathrm{x}}$ & 2.00 & 4.00 & 2.67 & 2.89 \\
\hline & $\mathrm{SD}$ & .000 & .000 & 1.15 & 1.05 \\
\hline \multirow[t]{2}{*}{ Estimate of Solution Correctness (EOSC) } & $\mathrm{X}$ & 2.67 & 4.00 & 3.00 & 3.22 \\
\hline & $\mathrm{SD}$ & .577 & .000 & .000 & .667 \\
\hline \multirow[t]{2}{*}{ Feeling of Confidence (FOC) } & $\overline{\mathrm{x}}$ & 3.33 & 4.00 & 3.00 & 3.44 \\
\hline & $\mathrm{SD}$ & .577 & .000 & .000 & .527 \\
\hline \multirow[t]{2}{*}{ Feeling of Satisfaction (FOS) } & $\overline{\mathrm{X}}$ & 3.00 & 4.00 & 3.00 & 3.33 \\
\hline & $\mathrm{SD}$ & .000 & .000 & .000 & .500 \\
\hline
\end{tabular}

The levels of SMME in Table 1 explain the effect of CMA on students' SMME across ability groups. The participants across ability exhibited very high feelings of liking (FOL), high feelings of difficulty (FOD), high estimates of effort (EOE), high estimates of time (EOT), high estimates of solution correctness (EOSC), high feelings of confidence (FOC), and high feelings of satisfaction (FOS). This SMME across ability groups are observed to be different. Using the Kruskal-Wallis test, Table 2 revealed that only EOSC and FOS are statistically significant across ability groups at .05 level of significance.

Table 2: Significant differences in socially motivated metacognitive experiences across ability groups

\begin{tabular}{llll}
\hline Metacognitive Experiences & $\chi^{2}$ & $\boldsymbol{d f}$ & $\boldsymbol{p}$-value \\
\hline Feeling of Liking (FOL) & 1.14 & 2 & .565 \\
\hline Feeling of Difficulty (FOD) & 1.54 & 2 & .464 \\
\hline Estimate of Effort (EOE) & 4.88 & 2 & .087 \\
\hline Estimate of Time (EOT) & 5.60 & 2 & .061 \\
\hline Estimate of Solution Correctness (EOSC) & 7.00 & 2 & $.030^{*}$ \\
\hline Feeling of Confidence (FOC) & 5.60 & 2 & .061 \\
\hline Feeling of Satisfaction (FOS) & 8.00 & 2 & $.018^{*}$ \\
\hline
\end{tabular}

Pairwise comparison of SMME across ability groups, both the high ability and low ability groups experienced high $\operatorname{EOSC}\left(\chi^{2}(1)=1.00, p>.05\right)$ and high FOS $\left(\chi^{2}(1)=0.00, p>.05\right)$. Conversely, the average ability group experienced very high EOSC compared to the high ability group $\left(\chi^{2}(1)=4.50, p<.05\right)$ and low ability group $\left(\chi^{2}(1)=5.00, p<.05\right)$. Furthermore, the average ability group had a very high FOS compared to the high ability group $\left(\chi^{2}(1)=5.00, p<.05\right)$ and low ability group $\left(\chi^{2}(1)=5.00, p<.05\right)$.

To establish how CMA affects students' SMME, Gamma statistics was used. Across ability groups, students' feedback request on the assessment of strategy showed high degree of correlations with students' EOT $(G=-.100, p<.01)$, EOSC $(G=-.714, p<.001)$, FOC $(G=-.1000, p<.01)$, and FOS $(G=-.1000, p<.05)$ in solving the GCTs. Surprisingly, other monitoring transactive responses on the assessment of strategy also revealed high degrees of correlation with SMME such as $\operatorname{EOT}(G=1.000, p<.001), \operatorname{EOSC}(G=1.000, p<.001)$, FOC $(G=1.000, p<.001)$, and FOS $(G=1.000, p$ $<.001)$ across ability groups.

While feedback requests on the assessment of results have a high degree of correlation with FOL $(G=-1.000, p<.05)$, other monitoring responses on the assessment of results are observed to have a moderate degree of correlation with EOT $(G=-.684, p<.05)$ across ability groups, feedback request on the assessment of understanding showed a high degree of correlation with FOL $(G=1.000, p<.05)$ and a moderate degree of correlation with FOD $(G=.619, p<.05)$, respectively. Furthermore, other monitoring responses on the assessment of understanding are highly correlated with $\operatorname{EOT}(G=1.000, p<.001), \operatorname{EOSC}(G=1.000, p<.001)$, FOC $(G=1.000, p<.001)$, and FOS $(G=1.000, p<.001)$ across ability groups. 
In this section, the results connote that successful collaboration is more than just active participation and dyadic dependence between the members of the high ability and average ability groups. The interpersonal metacognitive networks of each member contribute to the groups' knowledge of the strategy and tasks at hand (Jagals \& Van der Walt, 2016). Similar to Lawanto and Santoso (2013), students with high collaborative networks performed better than their low group counterparts due to the use of cognitive monitoring and regulation strategies. Likewise, the low ability group failed to solve problems because they did not use monitoring and evaluating monitoring skills (Ijirana \& Supriadi, 2018). Moreover, the high ability and the average ability groups were successful because of their meta social awareness and effective monitoring of processes and understanding (Siegel, 2011).

Although the findings of this study negate Chen et al. (2012), the generation of a new idea was irrelevant during successful problem-solving. The results confirm the findings of Fabelico (2014) and Goos et al., (2002). Successful collaboration is dependent on transactive discussions that are made open for judicial feedbacking. Moreover, the successful groups' feedback requests and other monitoring responses affect their FOD, FOL, EOT, EOSCC, FOC, and FOS during the assessment of understanding, strategies, and results. The metacognitive function on the evaluation of strategy affects FOD. Other monitoring transactive structure influences FOD and EOE during problem-solving (Fabelico, 2014). The reciprocal interaction enabled students to do metacognitive thinking in a collaborative situation (Hurme et al., 2006) that reduces an individual's FOD during problem-solving (Hurme et al., 2009). Thus, these findings suggest that the successful collaboration entails complex processes of coregulation of learning (Dindar et al., 2020b) and co-construction of socially motivated metacognitive experiences during chemistry problem-solving methods.

\section{Collaborative Metacognitive Activities and Socially Motivated Metacognitive Experiences across Chemistry Tasks}

In Figure 2, both the successful and unsuccessful groups displayed an "egalitarian triadic pattern" (Koponen \& Nousiainen, 2018) in solving the algorithmic tasks. This balanced mechanism characterized a transitive triad or threecycle closure. The pair of triads showed reciprocity, homophilic strong positive ties, and dyadic dependence between the members (Lou et al., 2013; Qian \& Adali, 2014). Examining closely, the successful and unsuccessful groups had the comparable total number of utterances. For the successful group, students A1, A2, and A3 had the total number of statements as $46 \%, 23 \%$, and $31 \%$, respectively. While for the unsuccessful groups, students A4, A5, A6 had uttered $44 \%, 38 \%$, and $18 \%$, respectively.

ALGORITHMIC TASKS

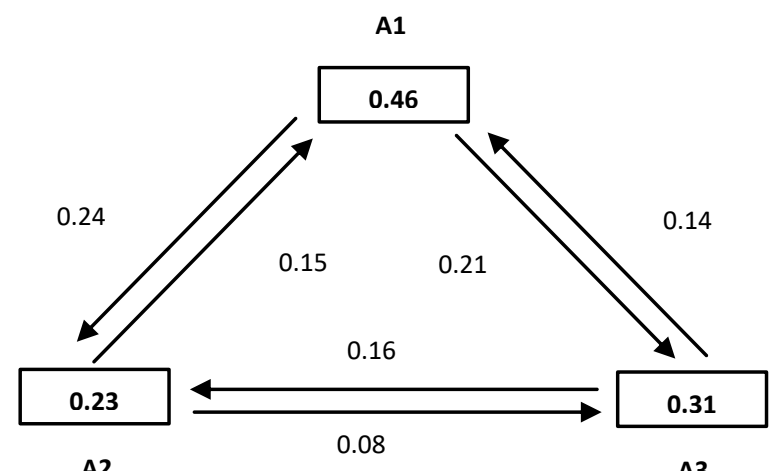

A2

Successful collaboration

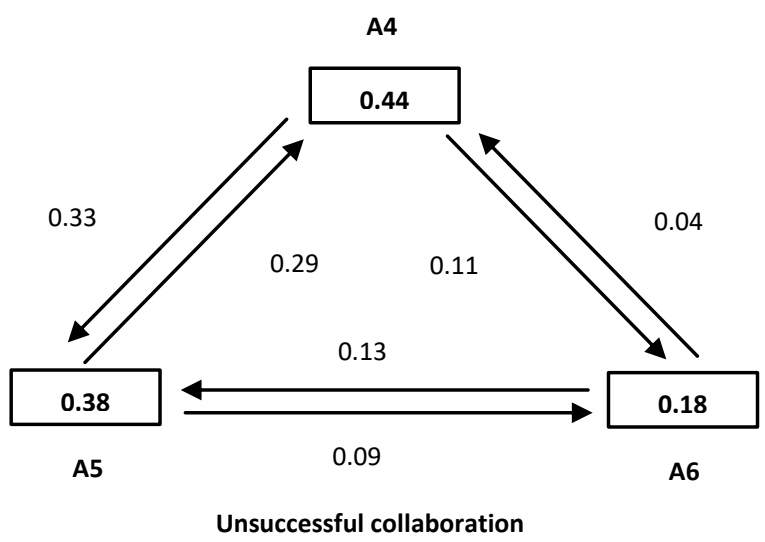

CONCEPTUAL TASKS
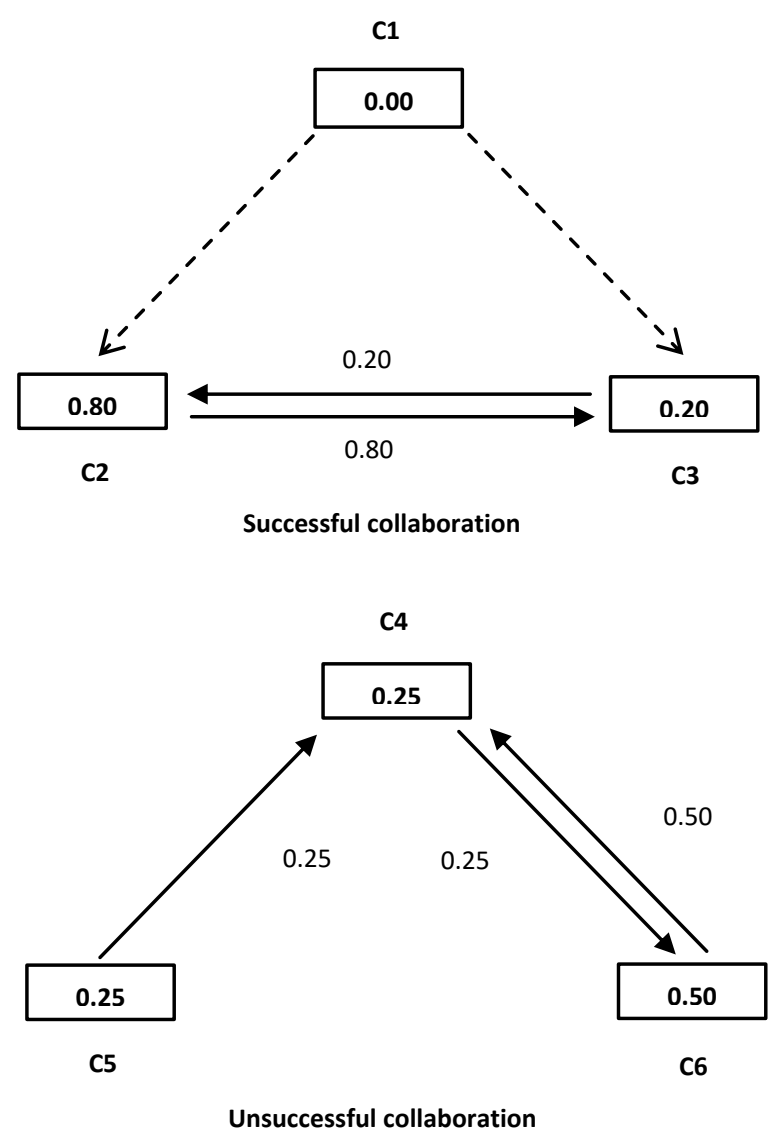

Figure 2: Collaborative metacognitive activities matrix of the participants in solving the group chemistry tasks 
By scrutinizing their CMA, the successful group exhibited feedback requests on the generation of a new idea (6.1\%), assessments of understanding (13.2\%), strategy (19.4\%), and results (8.1\%). This group also manifested other monitoring responses on the generation of new ideas (1.0\%) and assessment of understanding (18.4\%), strategy (22.5\%), and results $(11.2 \%)$. However, the unsuccessful group displayed feedback requests on the assessments of understanding (46.7\%), strategy $(8.9 \%)$, and results $(15.4 \%)$. Moreover, this group also displayed other monitoring responses on the assessment of understanding (19.9\%), and strategy $(8.8 \%)$. Thus, for collaboration to be successful in solving the algorithmic tasks, the CMA on feedback requests and other monitoring dialogues on the generation of a new idea, assessments of understanding, strategies, and results should be present.

Figure 2 further revealed the successful and unsuccessful groups had distinct differences in their interaction matrices during conceptual problem-solving. The CMA of the successful group had an "egalitarian dyadic pattern" (Koponen \& Nousiainen, 2018). In this balanced mechanism, the two members (C2, C3) are reciprocally symmetrical and isolated to the third member (C1). Both $\mathrm{C} 2 \leftrightarrow \mathrm{C} 3$ showed dyadic dependence and homophilic strong positive ties with each other during problem-solving (Lou et al., 2013; Qian \& Adali, 2014). Student C2 dominated the discussions in the group with $80 \%$ total number of utterances compared to student C3 with only $20 \%$. Although student $\mathrm{C} 1$ is just a spectator in the group, his nonverbal and friendly submissive behaviour helped his co-learners to proceed in their tasks as captured in the video records.

Furthermore, Figure 2 exposed that the unsuccessful group exhibited a "broker dyadic pattern" (Koponen \& Nousiainen, 2018) during conceptual problem-solving. This group had an unbalanced mechanism where one of the collateral members (C5) connects to one of the members (C4) in the dyad (C4↔C6). In this mechanism, student C5 failed in establishing a mutual relationship with the other two members because $\mathrm{C} 4 \leftrightarrow \mathrm{C} 6$ already had a strong homophilic positive relationship and dyadic dependence between each other (Lou et al., 2013; Quian \& Adali, 2014). Both students C4 and C5 had 25\% utterances each while student C6 had 50\% of the total number of statements in the group.

When the CMA of the successful groups were analyzed, the participants uttered feedback requests on the generation of an idea (20\%) and assessment of results (40\%). These groups also had other monitoring responses on the generation of ideas (20\%) and assessment of results (20\%). Conversely, the unsuccessful group exemplified CMA like feedback requests on the assessment of understanding (50\%) and results $(50 \%)$. There were no other monitoring responses observed in the unsuccessful group. Hence, successful collaboration during conceptual problem solving involves both feedback requests and other monitoring responses on the generation of a new idea and the assessment of results.

Across the types of chemistry tasks, Table 3 displays the effect of CMA on the levels of students SMME during problem-solving. The successful and unsuccessful groups experienced high FOL, high FOD, high FOS, high EOE, high EOT, high EOSC, and low FOC in solving their chemistry tasks.

Table 3: Means and standard deviations socially motivated metacognitive experiences across chemistry tasks

\begin{tabular}{|c|c|c|c|c|c|c|}
\hline \multirow[t]{2}{*}{ Metacognitive Experiences } & & \multicolumn{2}{|l|}{ Algorithmic } & \multicolumn{2}{|l|}{ Conceptual } & \multirow[t]{2}{*}{ Overall } \\
\hline & & Successful & Unsuccessful & Successful & Unsuccessful & \\
\hline \multirow[t]{2}{*}{ Feeling of Liking (FOL) } & $\overline{\mathrm{x}}$ & 3.00 & 2.33 & 3.33 & 3.00 & 2.92 \\
\hline & SD & 1.00 & .578 & .577 & .000 & .669 \\
\hline \multirow[t]{2}{*}{ Feeling of Difficulty (FOD) } & $\mathrm{x}$ & 3.00 & 3.00 & 2.00 & 3.00 & 2.75 \\
\hline & SD & .000 & .000 & .000 & .000 & .058 \\
\hline \multirow[t]{2}{*}{ Estimate of Effort (EOE) } & $\bar{x}$ & 3.00 & 3.00 & 2.67 & 3.00 & 2.92 \\
\hline & SD & 1.00 & .000 & .577 & .000 & .452 \\
\hline \multirow[t]{2}{*}{ Estimate of Time (EOT) } & $\overline{\mathrm{x}}$ & 3.00 & 3.00 & 2.33 & 3.00 & 2.83 \\
\hline & SD & 1.00 & .000 & .577 & .000 & .515 \\
\hline \multirow{2}{*}{$\begin{array}{l}\text { Estimate of Solution Correctness } \\
\text { (EOSC) }\end{array}$} & $\overline{\mathrm{x}}$ & 3.00 & 2.67 & 3.00 & 3.00 & 2.92 \\
\hline & SD & 1.00 & .577 & .000 & .000 & .577 \\
\hline \multirow[t]{2}{*}{ Feeling of Confidence (FOC) } & $\mathrm{x}$ & 2.33 & 2.33 & 3.00 & 2.33 & 2.50 \\
\hline & SD & .577 & .577 & .000 & .577 & .522 \\
\hline \multirow[t]{2}{*}{ Feeling of Satisfaction (FOS) } & $\mathrm{X}$ & 2.67 & 3.00 & 3.00 & 3.00 & 2.92 \\
\hline & SD & 1.15 & .000 & .000 & .000 & .515 \\
\hline
\end{tabular}

In Table 4, Kruskal-Wallis tests revealed that only FOD showed significant differences across chemistry tasks. Pairwise comparison of SMME across chemistry tasks showed that both the successful and unsuccessful groups had experienced high FOD $\left(\chi^{2}(1)=.000, p>.05\right)$ in solving the algorithmic tasks. The successful group experienced low FOD, while the unsuccessful group had experienced high FOD in solving the conceptual tasks $\left(\chi^{2}(1)=5.00, p<.05\right)$. Moreover, the successful group had experienced higher FOD in solving the algorithmic tasks than in the conceptual tasks $\left(\chi^{2}(1)=5.00\right.$, 
$p<.05)$. Conversely, the unsuccessful group had experienced high FOD in solving both types of chemistry tasks $\left(\chi^{2}(1)=\right.$ $.000, p>.05)$.

Gamma statistics were employed to justify further the effect of CMA on students' SMME in solving both types of chemistry tasks. Across chemistry tasks, feedback requests on the generation of new ideas showed a high degree of correlation with students' FOS $(G=-.810, p<.05)$. Both feedback requests and other monitoring responses on the assessment of strategy showed high degrees of correlation with FOD $(G=1.000, p<.05)$. Feedback requests on the evaluation of understanding also have high degrees of association with FOD $(G=1.000, p<.001)$ and FOC $(G=-.722, p$ $<.001)$. Furthermore, other monitoring responses on the assessment of understanding also have a high degree of correlation with FOD $(G=1.000, p<.01)$.

Table 4: Significant differences of socially motivated metacognitive experiences across chemistry tasks

\begin{tabular}{llll}
\hline Metacognitive Experiences & $\chi^{2}$ & $\boldsymbol{d f}$ & $\boldsymbol{p}$-value \\
\hline Feeling of Liking (FOL) & 3.63 & 3 & .304 \\
\hline Feeling of Difficulty (FOD) & 11.0 & 3 & $.012^{*}$ \\
\hline Estimate of Effort (EOE) & .956 & 3 & .812 \\
\hline Estimate of Time (EOT) & 3.19 & 3 & .364 \\
\hline Estimate of Solution Correctness (EOSC) & .956 & 3 & .812 \\
\hline Feeling of Confidence (FOC) & 3.67 & 3 & .300 \\
\hline Feeling of Satisfaction (FOS) & 1.20 & 3 & .753 \\
\hline
\end{tabular}

Across chemistry tasks, the findings affirm Aydin-Gunbatar \& Kalender (2019). The unsuccessful groups experienced difficulty in solving both the algorithmic and conceptual chemistry tasks. Students had alternative conceptions (Dahsah, \& Coll, 2013), lack procedural knowledge, and lack conceptual understanding (BouJaoude \& Barakat, 2003; Chiu, 2001; Sanger, 2005; Wood \& Breyfogle, 2006) of the stoichiometry concepts. However, the successful groups were able to solve the algorithmic and conceptual chemistry tasks correctly because the students had a sound understanding of the macroscopic, microscopic, and symbolic schemes of the stoichiometry concepts (Sujak \& Sarojini, 2017). The successful groups used effectively metacognitive processes (Ramadhan \& Pratana, 2020) and collaborative metacognitive activities during problem-solving (Goos et al., 2002). The results imply that the successful groups were able to reduce the feeling of difficulty during conceptual problem solving due to the scaffolding match between colearners' metacognitive experiences (Salonen et al., 2005).

\section{CONCLUSION}

Collaborative metacognitive activities affect quantitatively students' socially motivated metacognitive experiences in stoichiometric problem-solving across ability groups and chemistry tasks. Successful collaboration occurs across ability groups when the group exhibits equal dyadic leader or triadic patterns of social interactions. Moreover, successful collaboration occurs across ability groups when feedback requests and other-monitoring responses on the assessment of understanding and strategy influences students' estimates of solution correctness and feeling of satisfaction during problem-solving. Successful collaboration occurs in algorithmic and conceptual problem-solving when the group portrays an egalitarian triadic and dyadic pattern of social interactions, respectively. Furthermore, successful collaboration emerges when students' feedback requests and other monitoring responses on the assessments of understanding and strategy influence the feeling of difficulty in solving both types of chemistry tasks.

\section{LIMITATION AND STUDY FORWARD}

The current study involved several limitations such as the sample size. The sample size is relatively small. Future research should test larger sample size to validate the results of this study. Moreover, future studies should investigate how the dimensions of monitoring knowledge and metacognitive skills influence CMA and SMME during problemsolving.

\section{ACKNOWLEDGEMENT}

Special gratitude is given to the Nueva Vizcaya State University, Philippines for the support of this research endeavor.

\section{REFERENCES}

1. Akama, K. \& Yamauchi, H. (2004). Task performance and metacognitive expriences in problem solving. Psychological Reports, 94 (2): 715-722. https://doi.org/10.2466/pr0.94.2.715-722

2. Asik, G. \& Erktin, E. (2019). Metacognitive experiences: Mediating the relationship between metacognitive knowledge and problem solving. Education and Science, 44 (197): 85-103. https://pdfs.semanticscholar.org/5af5/eb186355bb9205073c0238a50b72e61a5cd9.pdf

3. Aydin-Gunbatar, S., \& Kalender, N. (2019). Comparison of learners' problem-solving approaches and success in stoichiometry. Science Education International, 30 (3): 169 - 180. 
4. BouJaoude, S. \& Barakat, H. (2003). Students' problem-solving strategies in stoichiometry and their relationships to conceptual understanding and learning approaches. Electronic Journal of Science Education, 7 (3): 1- 42. http://ejse.southwestern.edu/article/view/7709

5. Chen, G., Chiu, M., \& Wang, Z. (2012). Social metacognition and creation of correct, new ideas: A statistical discourse analysis of online mathematics discussions. Computers in Human Behavior, 28 (3): 868 - 880. https://doi.org/10.1016/j.chb.2011.12.006

6. Chiu, M.H. (2001). Algorithmic problem solving and conceptual understanding of chemistry by students at a local high school in Taiwan. Proc. Natl. Sci. Counc. ROC(D), 11 (1): 20 - 38. https://www.researchgate.net/profile/Mei-Hung_Chiu/publication/237216516

7. Choy, S., Yim, J., \& Tan, P. (2019). Mediating effects of quality learning on metacognitive knowledge, metacognitive experiences and outcomes. Issues in Educational Research, 29 (1): 1-18. http://www.iier.org.au/iier29/choy.pdf

8. Choy, S., Yim, J., \& Tan, P. (2020). A metacognitive knowledge, metacognitive experience, and its effects on learning outcomes for STEM and non-STEM Malaysian students. International Journal of Advanced Research in Education and Society, 2 (1): 1-14. http://myjms.moe.gov.my/index.php/ijares

9. Dahsah, C., \& Coll, R. (2013). Thai grade 10 and 11 students' conceptual understanding and ability to solve stoichiometry problems. Research in Science \& Technological Education, 25 (2): 227-241. ttps://doi.org/10.1080/02635140701250808

10. Dindar, M., Jarvela, S., \& Haataja, E. (2020a). What does physiological synchrony reveal about metacognitive expereinces and group performance? British Journal of Educational Technology. https://doi.org/10.1111/bjet.12981

11. Dindar, M., Jarvela, S., \& Jarvenoja, H. (2020b). Interplay of metacognitive experiences and performance in collaborative problem solving. Computers \& Education 154 (2020): 1-16. https://doi.org/10.1016/j.compedu.2020.103922

12. Efklides, A. (2002). Feelings of judgments as subjective evaluations of cognitive processing: How reliable are they? Psychology: The Journal of the Hellenic Psychological Society, 9 (2): 163-182. https://psycnet.apa.org/record/2002-15160-001

13. Efklides, A. (2006). Metacognition and affect: What can metacognitive experiences tell us about the learning process? Educational Research Review, 1: 3-14. https://doi.org/10.1016/j.edurev.2005.11.001

14. Efklides, A. (2009). The role of metacognitive experiences in the learning process. Psichothema, 29 (1): 76-82. http://www.redalyc.org/articulo.oa?id=72711818013

15. Efklides, A. (2014). How does metacognition contribute to the regulation of learning? An integrative approach. Psychological Topics, 23 (1): 1 -30. https://hrcak.srce.hr/120492

16. Efklides, A., Samara, A., \& Petropoulou, M. (1999). Feeling of difficulty: An asspect of monitoring that influences control. European Journal of Psychology of Education, 14 (4): 461 - 476. https://doi.org/10.1007/BF03172973

17. Etokeren, S., Ibemenji, K., \& Alamina, J. (2019). Effect of problem-solving teaching technique on students' stoichiometry academic performance in senior secondary school chemistry in Nigeria. Asian Journal of Advanced Research and Reports, 4 (3): 1 - 11. https://doi.org/10.9734/ajarr/2019/v4i330110

18. Fabelico, F.L. (2014). Social interaction and ability grouping: Their effects on students' metacognitive experiences in stoichiometric problem-solving. Asia Pacific Journal of Education, Arts and Sciences, 1 (4): 129-136. https://www.academia.edu/8553503

19. Flavel, J.H. (1979). Metacognition and cognitive monitoring: A new era for cognitive - Developmental inquiry. American Psychologist, 34 (10): 906- 911. https://doi.org/10.1037/0003-066X.34.10.906

20. Frith C. D. (2012). The role of metacognition in human social interactions. Philosophical Transactions of the Royal Society B, 367 (1599): 2213-2223. https://doi.org/10.1098/rstb.2012.0123

21. Goos, M., Galbraith, P., \& Renshaw, P. (2002). Socially mediated metacognition: creating collaborative zones of proximal development in small group problem-solving. Educational Studies in Mathematics, 49: 193-223. https://doi.org/10.1023/A:1016209010120

22. Gulacar, O., Tan, A., Cox, C. Jr., Bloomquist, J., Jimmy, O. \& Cao, N. (2019). Analyzing characteristics of experts in the context of stoichiometric problem-solving. Education Sciences, 9 (2019): 1-11. https://doi.org/10.3390/educsci9030219

23. Gupta, T. (2020). Promoting mathematical reasoning and problem solving through inquiry-based relevance focused computer simulations: A stoichiometry lab. Chemistry Teacher International, 1 (1): 1-12. https://doi.org/10.1515/cti-2018-0008

24. Hurme, TR., Merenluoto, K., \& Jarvela, S. (2009). Socially shared metacognition of pre-service primary teachers in a computer-supported mathematics course and their feelings of task difficulty: A case study. Educational Research and Evaluation: An International Journal on Theory and Practice, 15 (5): 503-524. https://doi.org/10.1080/13803610903444659

25. Hurme, TR., Palonen, T., \& Jarvela, S. (2006). Metacognition in joint discussions: An analysis of the patterns of interaction and the metacognitive content of the networked discussions in mathematics. Metacognition Learning, 1: 181 - 200. https://doi.org/10.1007/s11409-006-9792-5 
26. Iiskala, T., Volet, S., Lehtinen, E., \& Vauras, M. (2015). Socially shared metacognitive regulation in asynchronous CSCL in science: Functions, evolution and participation. Frontline Learning Research, 3 (1): 78 111. https://doi.org/10.1016/j.learninstruc.2015.04.001

27. Ijirana \& Supriadi. (2018). Metacognitive skills profiles of chemistry education students in solving at low ability level. Journal Pendidikan IPA Indonesia, 7 (2): 239-245, https://doi.org/10.15294/jpii.v7i2.14266

28. Iriani, R., Norjanah I., \& Kusasi M. (2019). The development of electronic publication module integrated with a means-end analysis learning model to improve students' analytical thinking skills in stoichiometry materials. Advances in Social Sciences, Education and Humanities Research, 407: 1 - 4. https://doi.org/10.2991/assehr.k.200219.056

29. Jagals, D. \& Van der Walt, M. (2016). Exploiting metacognitive networks embedded in narrative focus group interviews using NodeXL. The Qualitative Report, $21 \quad$ (10): 1868 - 1880. https://search.proquest.com/openview/df220566b53a685314586efec445eaea/

30. Koponen, I., \& Nousiainen, M. (2018). An agent-based model of discourse pattern formation in small groups of competing and cooperating members. Journal of Artificial Societies and Social Simulation, 2018; 2 (2): 1-22. https://doi.org/10.18564/jasss.3648

31. Kreijns, K., Kirschner P., \& Jochems, W. (2002). The sociability of computer-supported collaborative learning $\begin{array}{lllllll}\text { environments. } & \text { Educational Technology } \& & \text { Society, } & 5 & \text { (1): } & 1-22 .\end{array}$ https://www.jstor.org/stable/pdf/jeductechsoci.5.1.8.pdf

32. Lausin, F. (2020). The effects of using particulate diagrams on high school students' conceptual understanding of stoichiometry. Human Behavior, Development and Society, 21 (1): 68 - 77. https://so01.tcithaijo.org/index.php/hbds/article/view/240003/163658

33. Lawanto, O., \& Santoso, H. (2013). Students' collaborative note-taking activities while using electronic and paper-based enhanced guided notes: Viewed from metacognitive and social network perspectives. In Proc. 2013 IEEE Frontiers in Education Conference (FIE), Oklahoma City, OK, pp. 1190 - 1196. https://doi.org/10.1109/FIE.2013.6685018

34. Lou, T., Tang, J., Hopcroft, J., Fang, Z.,\& Ding, X. (2013). Learning to predict reciprocity and triadic closure in social networks. ACM Transactions on Knowledge Discovery from Data, 7 (2): 1 - 25. https://doi.org/10.1145/2499907.2499908

35. Makhechane, M. \& Qhobela, M. (2019). Understanding how chemistry teachers transform stoichiometry concepts at the secondary level in Lesotho, South African Journal of Chemistry, 72: 59-66. https://doi.org/10.17159/0379-4350/2019/v72a9

36. Mwambe, O. \& Kamioka, E. (2019). Utilization of learners' metacognitive experiences to monitor learners' cognition states in e-learning platforms. International Journal of Information and Education Technology, 9 (5): 362-365. https://doi.org/10.18178/ijiet.2019.9.5.1227

37. Norman, E. \& Furnes, B. (2016). The realtionshop between metacognitive experiences and learning: Is there a difference between digital and non-digital study media? Computers in Health Behavior, 54 (2016): 301-309. https://doi.org/10.1016/j.chb.2015.07.043

38. Qian, Y., \& Adali, S. (2014). Foundations of trust and distrust in networks: Extended structural balance theory. ACM Transactions on Knowledge Discovery from Data, 8 (3): 1- 33. https://doi.org/10.1145/2628438

39. Quatman, C. \& Chelladurai P. (2008). Social network theory and analysis: A complementary lens for inquiry. In Journal of Sport Management, 22 (3): 338-360. https://doi.org/10.1123/jsm.22.3.338

40. Radmehr, F., \& Drake, M. (2018). Students' mathematical performance, metacognitive experiences and metacognitive skills in relation to integral-area relationships. Teaching Mathematics and Its Applications, 38 (2): 85-106. https://doi.org/10.1093/teamat/hry006

41. Ramadhan, A., \& Pratana, C. (2020). Students' metacognition skill: How the implementation in chemistry learning? Journal of Physics: Conference Series: 1440: 1-7. https://doi.org/10.1088/1742-6596/1440/1/012013

42. Roeberts, C., Mayer, B., Steiner, M., Bayard, N., \& van Loon, M. (2019). The role of children's metacognitive experiences for cue utilization and monitoring accuracy: A longitudinal study. Development Psychology, 55 (10): 2077-2089. https://doi.org/10.1037/dev0000776

43. Salonen, P., Vauras, M., \& Efklides, A. (2005). Social Interaction - What can it tell us about metacognition and coregulation in learning? European Psychologist, 10 (3): 199 - 208. https://doi.org/10.1027/1016-9040.10.3.199

44. Sanger, M. J. (2005). Evaluating student' conceptual understanding of balanced equations and stoichiometric ratios using a particulate drawing. Journal of Chemical Education, 82 (1): 131-134. https://doi.org/10.1021/ed082p131

45. Sangguro, S., Surif, J., Ibrahim, N., \& Bunyamin, M. (2020). Procedural knowledge in stoichiometry problem $\begin{array}{llllll}\text { solving. Talent Development \& Excellence, } 12 & \text { (2): 1635-1643. }\end{array}$ http://iratde.com/index.php/jtde/article/view/690

46. Sanna, L. \& Schwarz, N. (2018). Metacognitive experiences and human judgment. Current Directions in Psychological Science, 15 (4): 172-176. https://doi.org/10.1111/j.1467-8721.2006.00430.x

47. Scott, A. (2020). Influence of context on stoichiometry conceptual and algorithmic subject matter knowledge among South African Physical Sciences Teachers. Journal of Chemical Education. 97 (5): 1239-1246. https://doi.org/10.1021/acs.jchemed.9b01056 
48. Shadreck, M. \& Enunuwe, O. (2018). Recurrent Difficulties: Stoichiometry problem-solving. African Journal of Educational Studies in Mathematics and Sciences, $14: \quad 25 \quad-\quad 31$. https://www.ajol.info/index.php/ajesms/article/view/173393

49. Siburt, C., Bissell, A., \& Macphail, R. (2011). Developing metacognitive and problem skills through problem manipulation. Journal of Chemical Education, 88 (11): 1489 - 1495. https://doi.org/10.1021/ed100891s

50. Siegel, M. A. (2011). Filling in the distance between us: Group metacognition during problem-solving in a secondary education course. Journal of Science Education and Technology, 2011; 21: 325-341. https://doi.org/10.1007/s10956-011-9326-Z

51. Stamovlasis, D., Dimos, A., \& Tsaparlis, G. (2006). A study of group interaction processes in learning lower secondary physics. Journal of Research in Science Teaching, 43 (6): 556-576. https://doi.org/10.1002/tea.20134

52. Sujak K. B. \& Sarojini E. G. (2017). Understanding of macroscopic, microscopic and symbolic representations among form four students in solving stoichiometric problems. MOJES: Malaysian Online Journal of Educational Sciences, 5 (3): 83 - 96. https://mojes.um.edu.my/article/view/12627

53. Syahmani. (2015). Using metacognitive skills in learning chemistry through problem-solving. In Proc. International Seminar Chemistry Education, Indonesia, 234 - 244. http://eprints.ulm.ac.id/id/eprint/2611

54. Thomas, G.P. \& McRobbie, C.J. (2012). Eliciting metacognitive experiences and reflection in year 11 chemistry classroom: An activity theory perspective. Journal of Science Education and Technology, 21 (3): 1 16. https://doi.org/10.1007/s10956-012-9394-8

55. Wood, C. \& Breyfogle, B. (2006). Interactive demonstrations for mole ratios and limiting reagents. Journal of Chemical Education, 88 (5): 741-743. https://doi.org/10.1021/ed083p741 